Supplement of Nat. Hazards Earth Syst. Sci., 18, 2081-2092, 2018

https://doi.org/10.5194/nhess-18-2081-2018-supplement

(c) Author(s) 2018. This work is distributed under

the Creative Commons Attribution 4.0 License.

(c) (1)

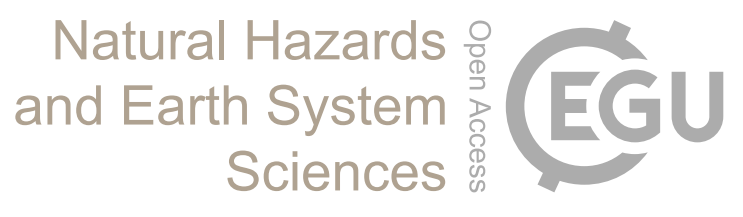

Supplement of

\title{
Assessment of the peak tsunami amplitude associated with a large earth- quake occurring along the southernmost Ryukyu subduction zone in the region of Taiwan
}

\section{Yu-Sheng Sun et al.}

Correspondence to: Yu-Sheng Sun (shengfantasy@gmail.com)

The copyright of individual parts of the supplement might differ from the CC BY 4.0 License. 
Thirty stations located along the coastlines are available for recording the amplitude of the tsunami wave height. The time series of the wave heights at Station 1 to 24 and 28 to 30 are shown in the supplement.

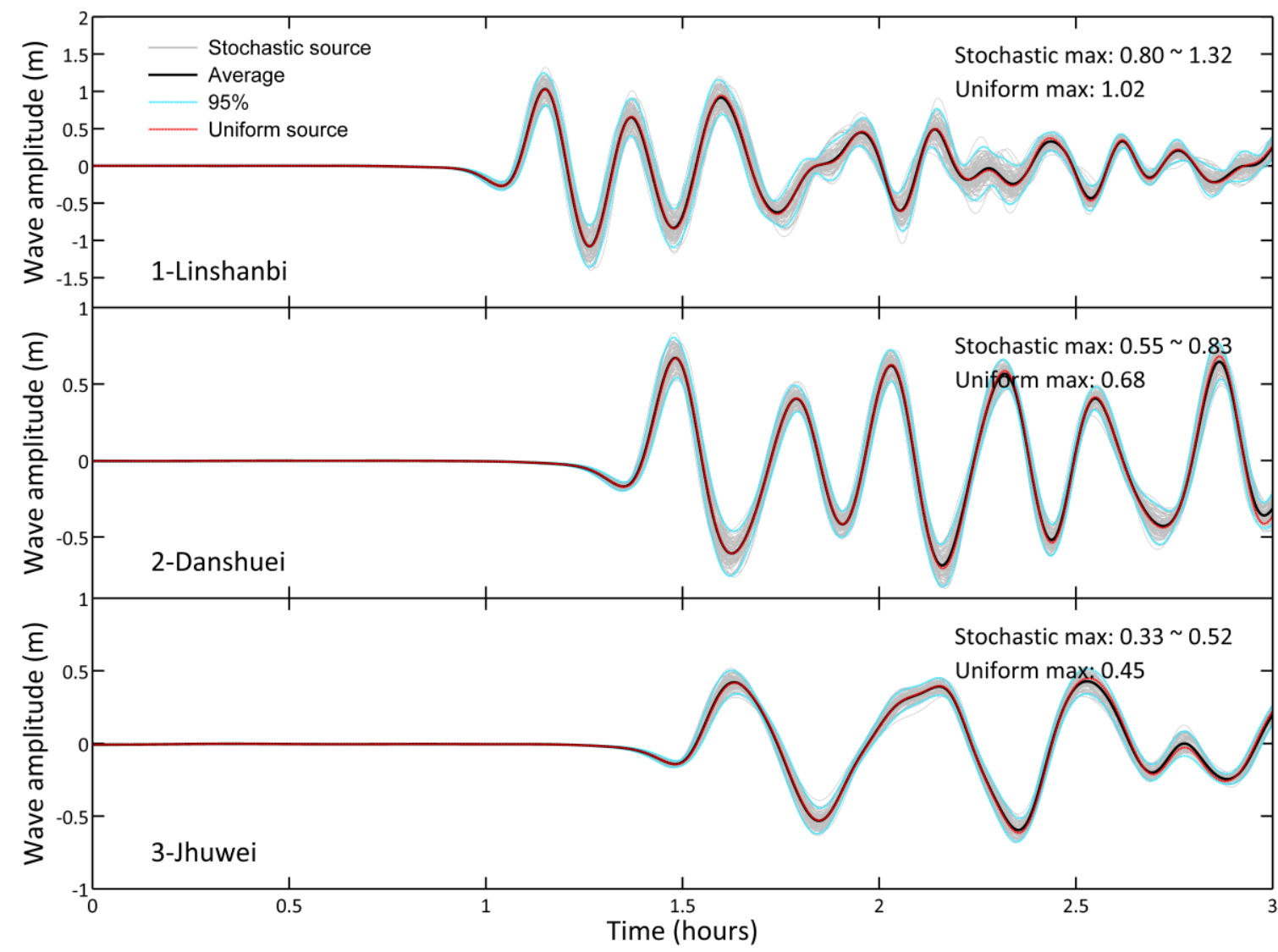

Figure 1. The time series of the wave heights recorded at stations 1 (Linshanbi), 2 (Danshuei) and 3 (Jhuwei). 


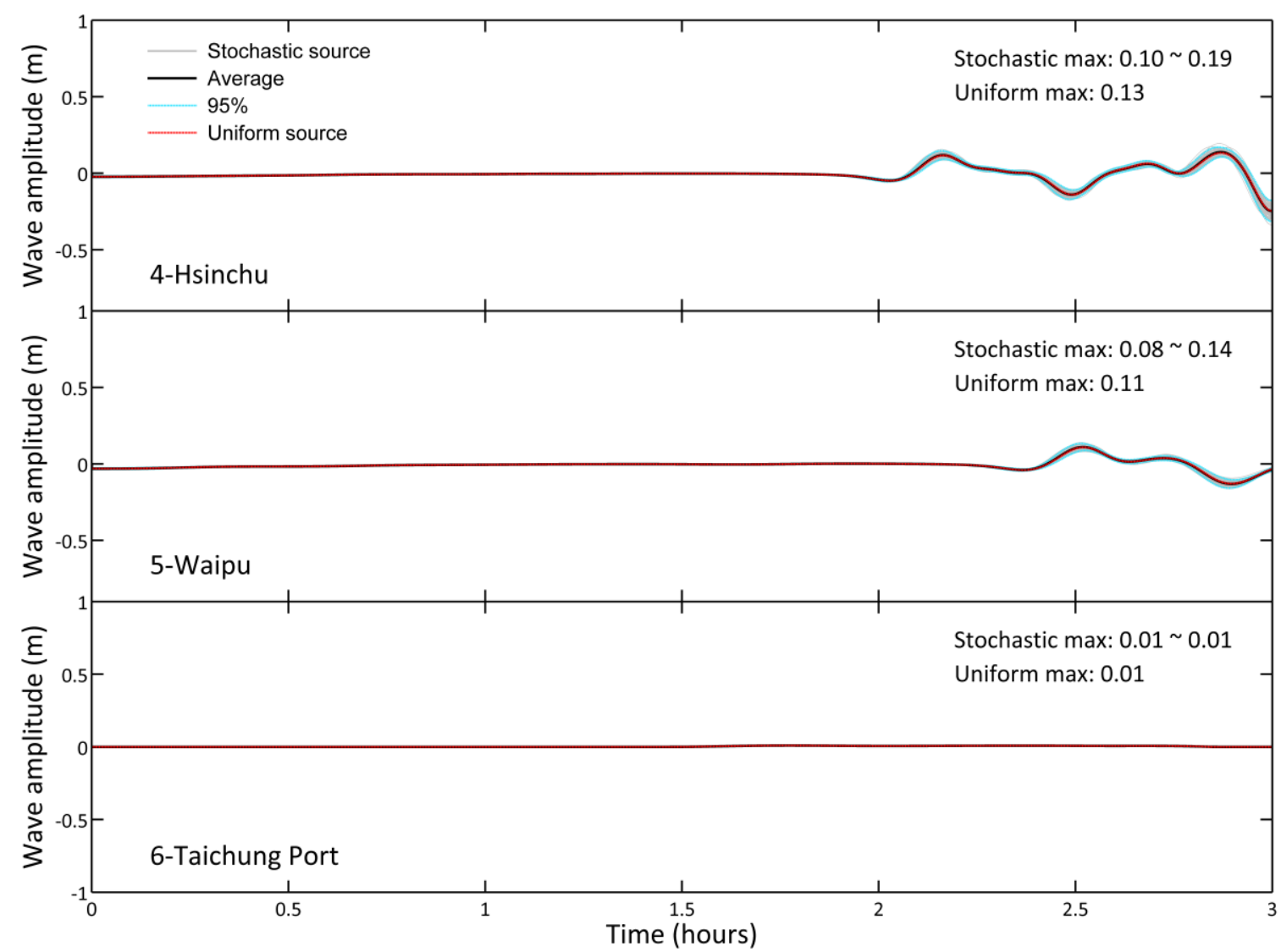

Figure 2. The time series of the wave heights recorded at stations 4 (Hsinchu), 5 (Waipu) and 6 (Taichung Port). 


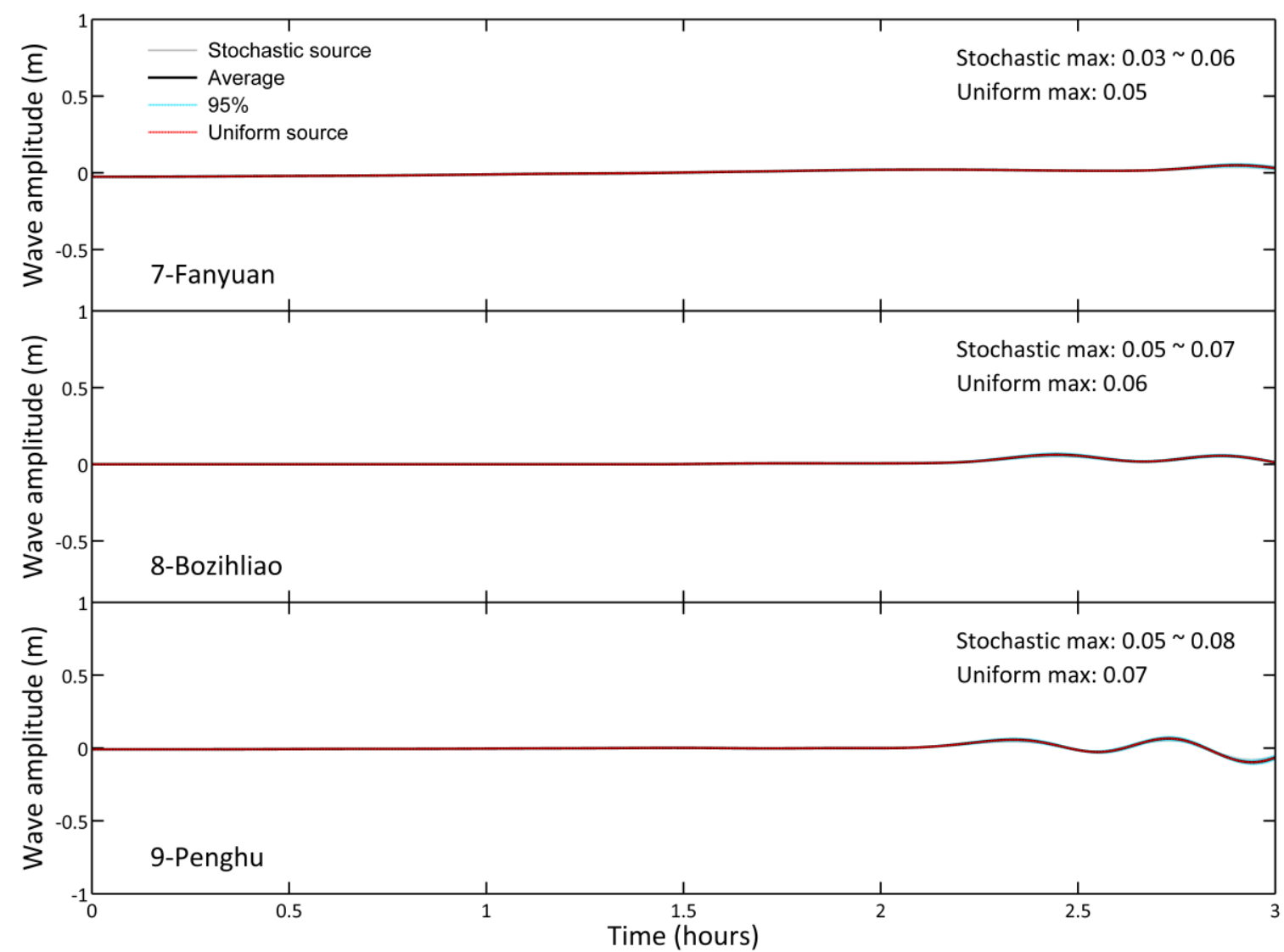

Figure 3. The time series of the wave heights recorded at stations 7 (Fanyuan), 8 (Bozihliao) and 9 (Penghu). 


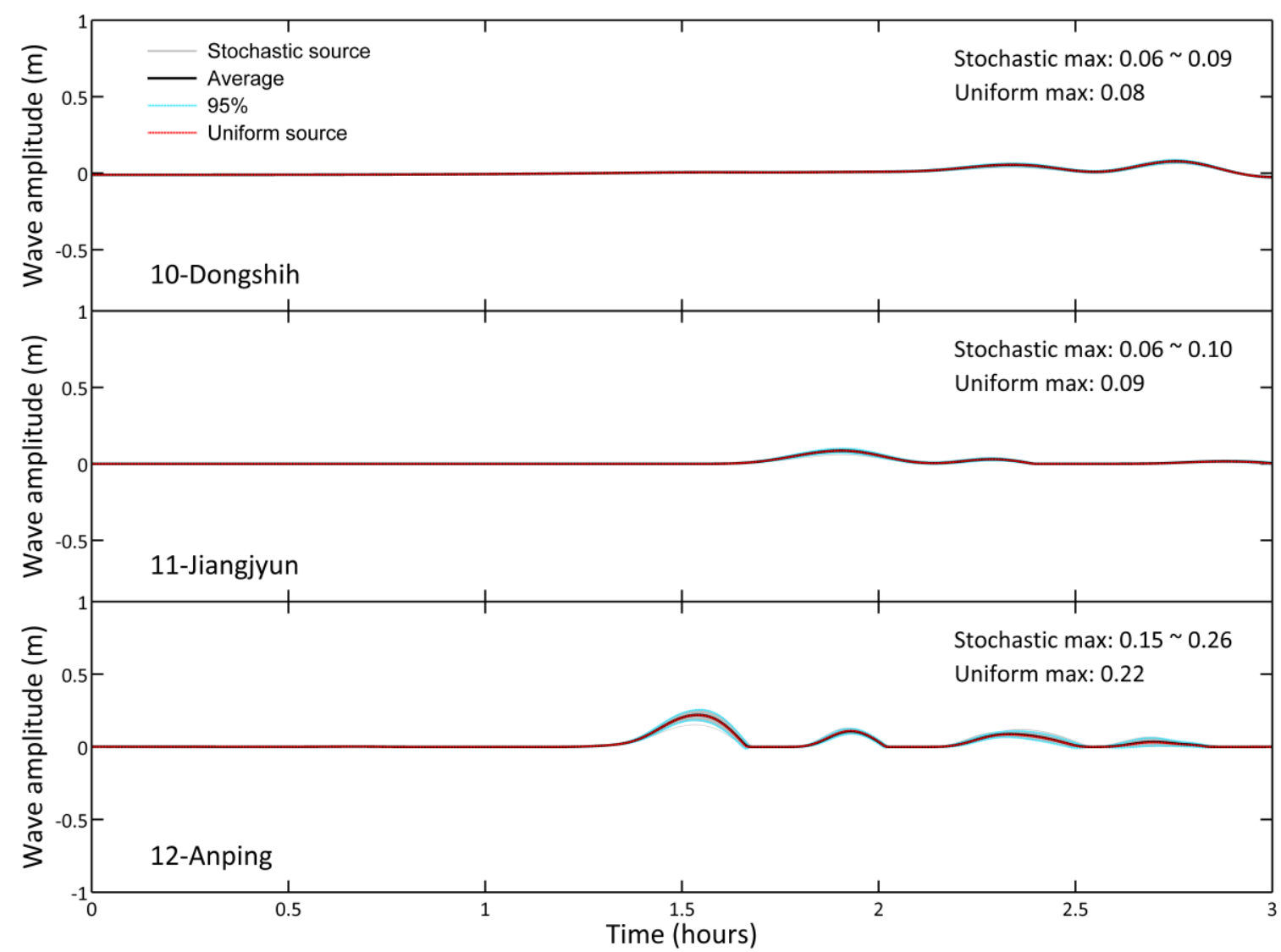

Figure 4. The time series of the wave heights recorded at stations 10 (Dongshih), 11 (Jiangjyun) and 12 (Anping). 


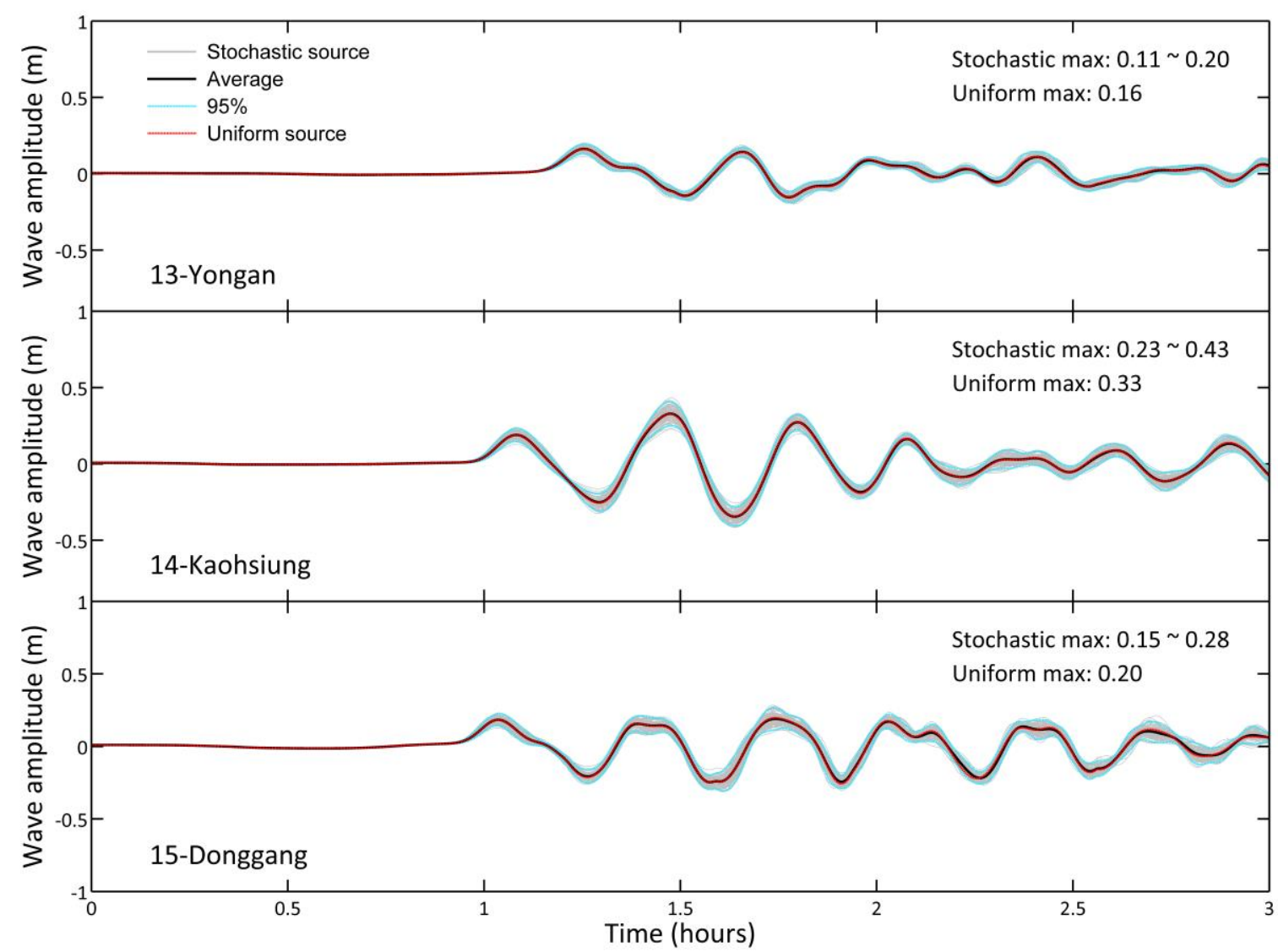

Figure 5. The time series of the wave heights recorded at stations 13 (Yongan), 14 (Kaohsiung) and 15 (Donggang). 


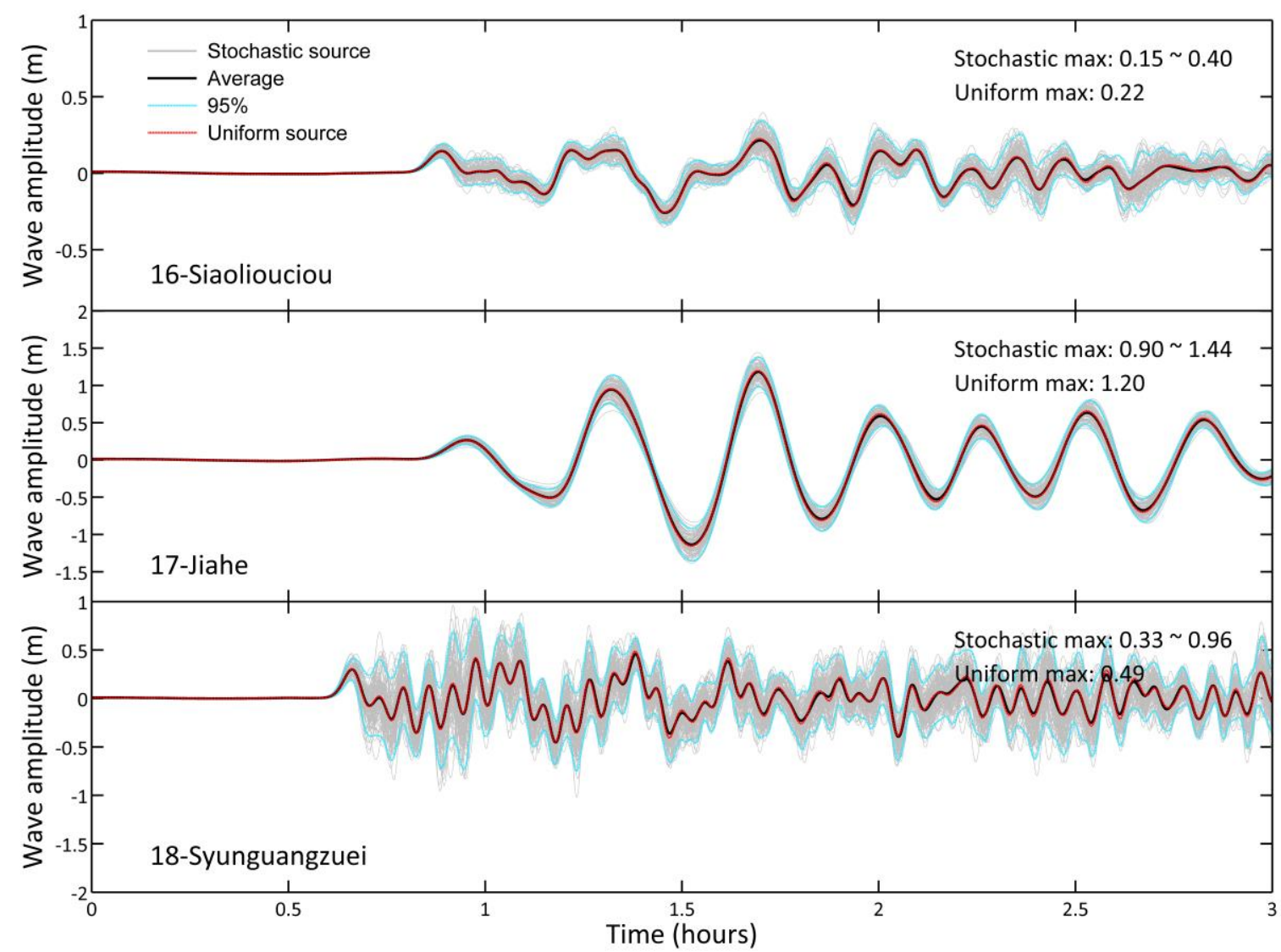

Figure 6. The time series of the wave heights recorded at stations 16 (Siaoliouciou), 17 (Jiahe) and 18 (Syunguangzuei) 


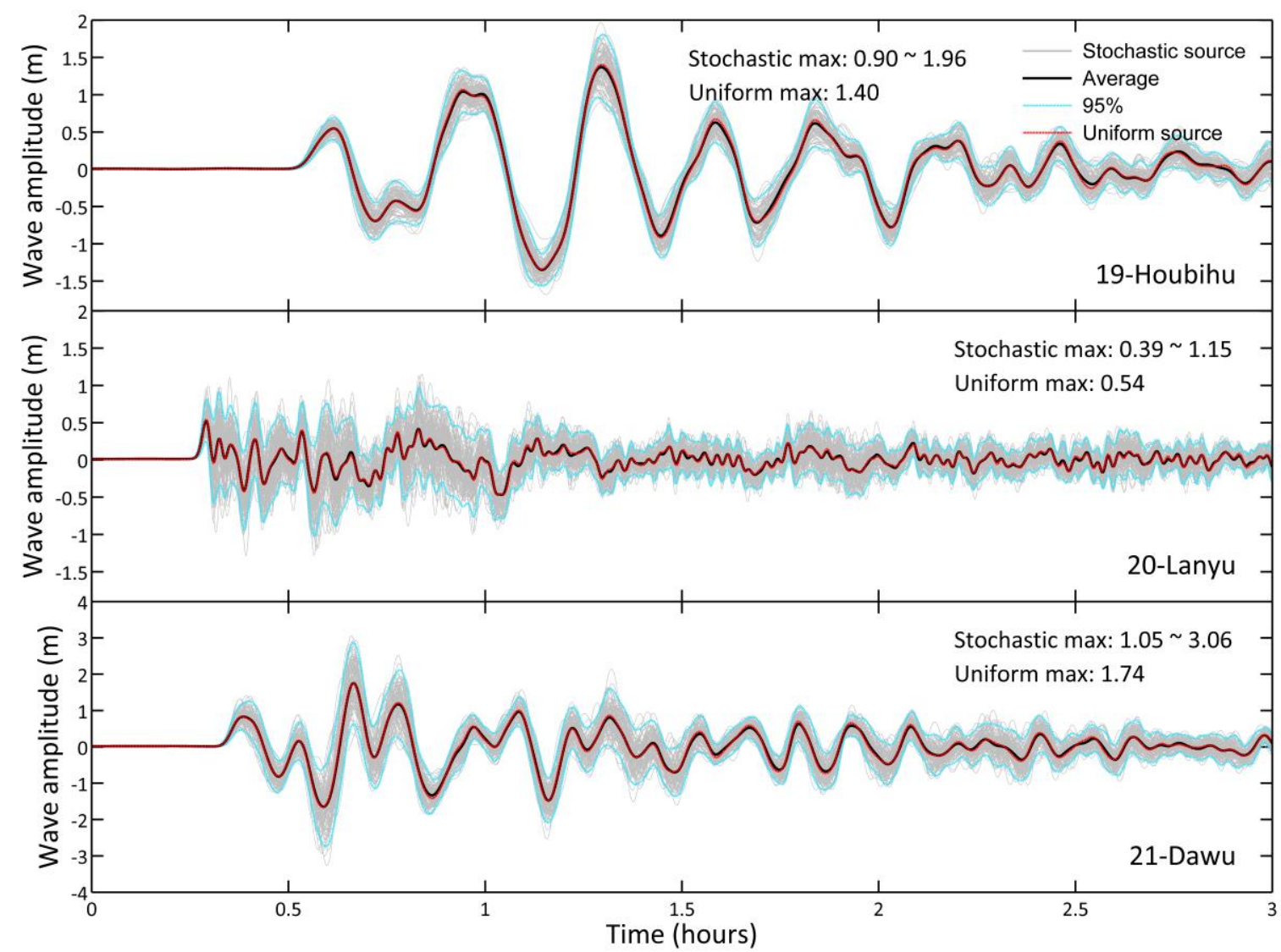

Figure 7. The time series of the wave heights recorded at stations 19 (Houbihu), 20 (Lanyu) and 21 (Dawu). 


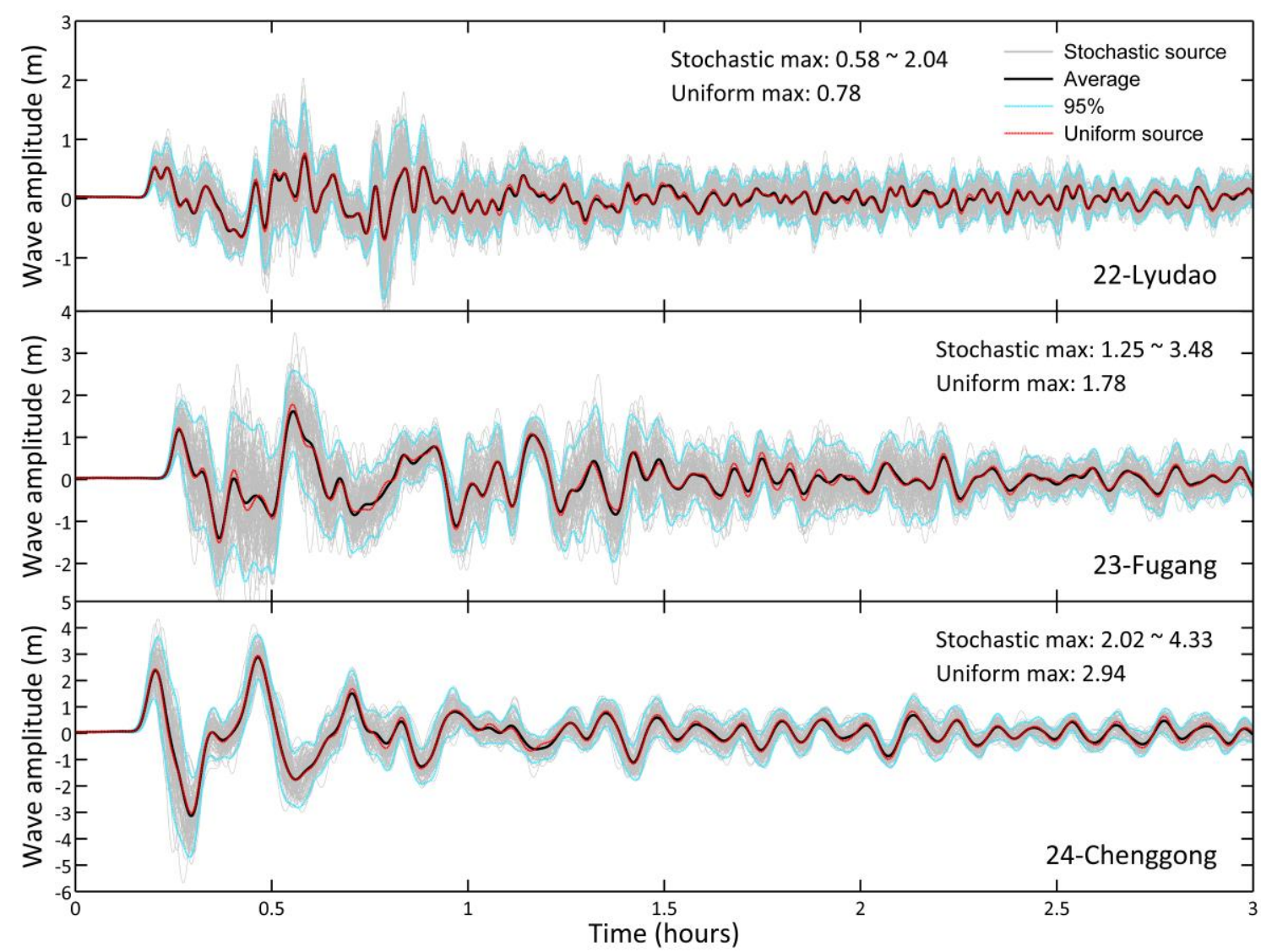

Figure 8. The time series of the wave heights recorded at stations 22 (Lyudao), 23 (Fugang) and 24 (Chenggong). 


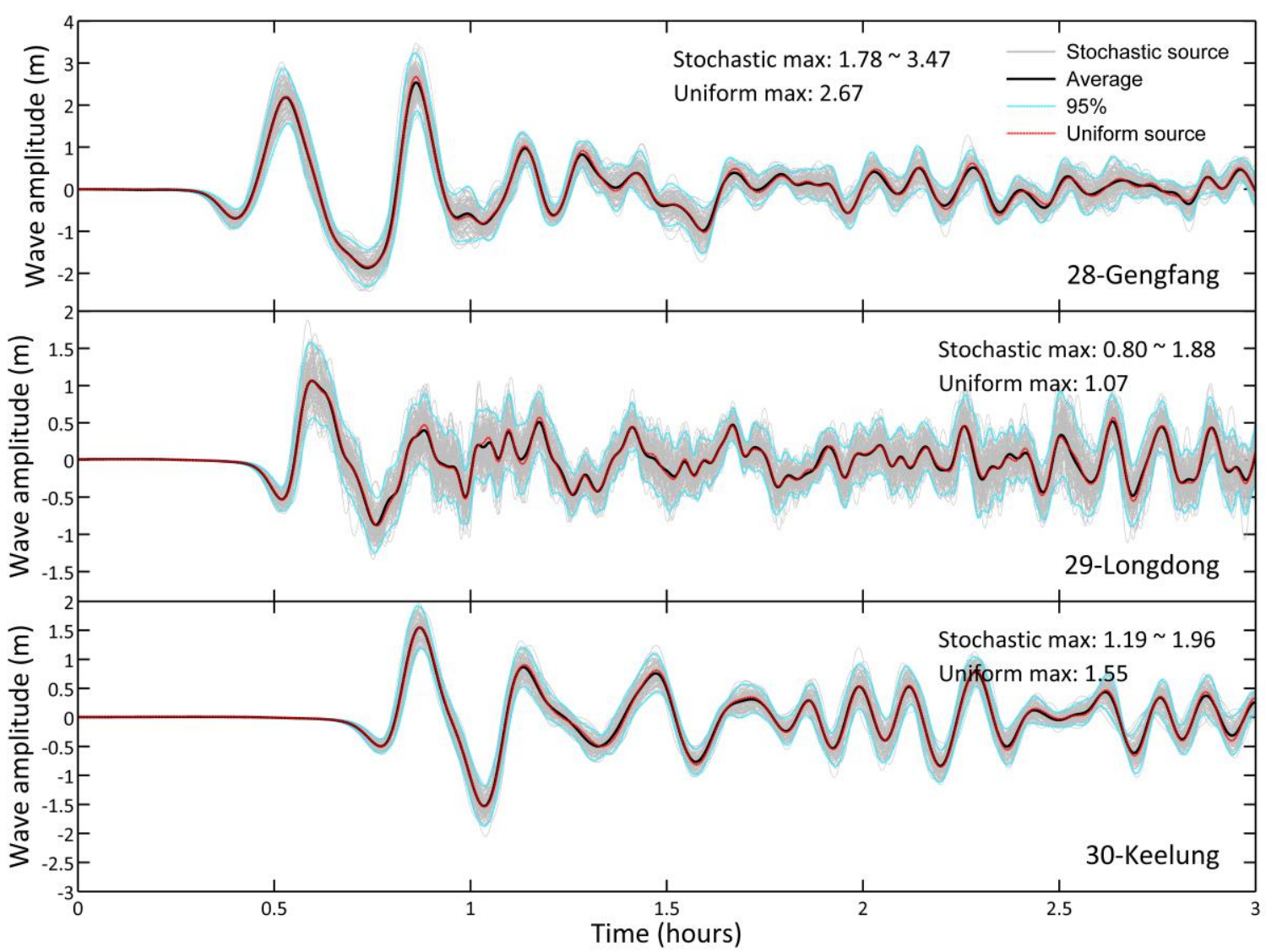

Figure 9. The time series of the wave heights recorded at stations 28 (Gengfang), 29 (Longdong) and 30 (Keelung). 